\title{
ROLE OF POLYMORPHISM OF METHYLTETRAHYDROFOLATE- HOMOCYSTEINE METHYLTRANSFERASE (MTR) A2756G AND BREAST CANCER RISK
}

\author{
Mojgan Hosseini
}

Department of Science, Islamshahr Branch, Islamic Azad University, Teheran, Iran

\begin{abstract}
Breast cancer (BC) is one of the most common causes of death among women, and second in Iran. The objectives of this study were to determine the frequency of methyltetrahydrofolate-homocysteine methyltransferase (MTR) 2756 gene polymorphism in patients with breast cancer. For the first time, we evaluated these polymorphisms and effects on the breast cancer risk association in an Iranian sporadic populationbased case-control study of 282 breast cancer cases and 310 controls using a PCRRFLP-based assay. Analyses of affected and controls show that homozygote genotype MTR 2756 AA has the highest frequency in both groups (33.3 in patients). Genotype MTR 2756 GG was the highest risk factor in our population $[\mathrm{AG} / \mathrm{GG}$ odds ratio, 0.329 (95\% CI: 0.146-0.741) p = 0.006, AA/AG, OR, 2.316, 95\% CI: 1.509$3.555, \mathrm{p}=0.001, \mathrm{AA} / \mathrm{GG}$ odds ratio, 0.761 (95\% CI: 0.363-1.595) $\mathrm{p}=0.297$ ]. There was a significant association of breast cancer risk with MTR 2756 GG and AA polymorphism.
\end{abstract}

Key words: MTR A2756G gene, polymorphism, breast cancer, HaeIII, PCR-RFLP.

\section{Introduction}

Little is known about the role of polymorphisms associated with breast cancer risk so not only is it studied for the first time upon our population about breast cancer but also there are different results compared to in another country.

DNA methylation is critical for regulating gene expression [1]. Methionine synthase is a vitamin $\mathrm{B}_{12^{-}}$ dependent enzyme, which catalyzes the remethylation of homocysteine to methionine and the concurrent demethylation of 5-methyltetrahydrofolate to tetrahydrofolate.

Folate metabolism has an important role in carcinogenesis because of involvement in both DNA methylation and nucleotide synthesis. DNA methylation is the transfer of methyl groups $(\mathrm{CH} 3)$ to the C5 position of cytosine residues located in cytosineguanine dinucleotides, by DNA methyltransferases [2] maintaining genomic and chromatin structure stability
$[3,4]$ and has roles including control of gene expression [5].

Methionine synthase has a role maintaining adequate intracellular folate, methionine. Methionine is an essential amino acid and is involved in methylation reactions including DNA methylation [6]. The 5-methyltetrahydrofolate-homocysteine methyltransferase (MTR) gene is located on chromosome 1q43 [7].

A common polymorphism in the methionine synthase (MTR) gene (2756A $\rightarrow \mathrm{G}, \mathrm{rs} 1805087)$ associated with lower enzyme activity than MTR 2756AA genotype, causing homocysteine elevation and DNA hypomethylation [8], encodes the methionine synthase enzyme (which has a role in folate metabolism), remethylating homocysteine (Hcy) to methionine [9].

There are a large number of molecular epidemiological studies on the role of MTR polymorphism in different kinds of neoplasm.

However, the association between polymorphism and cancer risk is still controversial. Some studies have shown 
associations with colon $[10]$, lung $[11]$ and breast cancer $[12]$.

Breast cancer is an increasingly important cause of illness and death among women so the aim of the present study was to attempt to elucidate a role for MTR 2756 (rs 1805087) as a high risk of breast cancer using the PCR-RFLP method.

Polymorphisms in genes encoding enzymes of folate metabolism are a focus of breast cancer risk studies due to the role of these enzymes in DNA methylation, synthesis, and repair.

MTR catalyzes the remethylation of homocysteine to methionine, which is essential for maintaining adequate intracellular methionine and normal homocysteine concentrations [13].

To our knowledge, this is the first study to investigate the association between polymorphisms of the MTR gene and risk of breast cancer in the Iranian population.

We report here the allele of MTR 2756 GG association in breast cancer patients in Iran.

\section{Material and methods}

\section{Patients' data}

Analyses were conducted for 282 patients and 310 controls genotyped for MTR 2756 and ages were 3555 years.

This study ethically was approved by the local Ethical Committee of Islamic Azad University from the point of view of patients' and also control group members' rights.

All patients participated in the Special Medical Centre, part of chemotherapy, Tehran, Iran. A questionnaire including questions on breast cancer risk factors was completed and each patient filled in a consent form. Data on the histologic type of breast cancer were phase II and III of carcinoma, and patients had metastases to lymph nodes but spread to distant organs only in a few patients in muscle, hands and behind the neck.

The blood samples were collected from patients and controls prior to the start of treatment. Subjects were

Table I. MTR 2756 genotype frequencies [n (\%)] for cases and controls: Analyses of 282 affected women and 310 controls for AA MTR 2756 genotype frequency show the highest frequency in both groups (33.3), and then in A/G MTR 2756 genotype (12.3) in the case group. The AG heterozygote genotype MTR 2756 is higher in the case group (12.3) compared with controls (6.8)

\begin{tabular}{lcccc}
\hline $\begin{array}{l}\text { STUDY } \\
\text { GROUP }\end{array}$ & N & GG & AA & AG \\
\hline Patient & 282 & $14(2.0 \%)$ & $197(33.3 \%)$ & $72(12.3 \%)$ \\
\hline Control & 310 & $20(3.4 \%)$ & $250(42.2 \%)$ & $40(6.8 \%)$ \\
\hline Total & 609 & $32(5.4 \%)$ & $447(75.5 \%)$ & $113(19.1 \%)$ \\
\hline
\end{tabular}

genotyped for the MTR 2756 SNP using genomic DNA extracted from peripheral blood lymphocytes. DNA was isolated from peripheral blood using the FlexiGene DNA extraction kit (Qiagen Germany).

\section{Genotyping}

The polymorphisms were detected using a modified PCR-RFLP method [14, 15]. The PCR primers were synthesized by TAG Copenhagen A/S. Primers were for each polymorphism as follows. The primers of $M T R$ A2756G were forward 5'-TGTTCCAGACAGTTAGATGAAAATC-3' and reverse 5'-GATCCAAAGCCTTTTACACTCCTC-3' [16]. The cycling conditions were $94^{\circ} \mathrm{C}, 30 \mathrm{~s} ; 57^{\circ} \mathrm{C}, 30 \mathrm{~s} ; 72^{\circ} \mathrm{C}, 60 \mathrm{~s}$ ( 35 cycle). The PCR products were digested with 1 unit of $\mathrm{HaeIII}$ (New England Biolabs, Beverly, MA), and the amplified fragment of 211 bp was cut into fragments of 131 and 80 bp and separated on a $6 \%$ acrylamide gel.

This method is able to detect all three possible genotypes for the polymorphism: homozygous wild type, heterozygous variant type and homozygous variant type.

The genotypes and allelic frequencies of MTR polymorphisms in patient and control groups were analyzed by $\chi^{2}$ and Fisher's exact tests.

\section{Results}

The aim of the present study was to attempt to elucidate a role for MTR 2756 as a high risk of breast cancer using the PCR-RFLP method, because the study was done for the first time upon our population and there have been few studies in other countries.

There was a significant association between MTR 2756 polymorphism and breast cancer risk.

Analyses of affected and controls show that heterozygote genotype MTR 2756 AA has the highest frequency in both genotypes (33.3) in the patient group.

On the other hand, even the heterozygote genotype in MTR 2756 AG has an increase in frequency compared with the control group (12.3 in patients and 6.8 in the control group) (Table I) (Fig. 1).

The $\mathrm{P}$ value of our results showed that the genotype MTR 2756 GG was the highest risk factor in our population: $\mathrm{AG} / \mathrm{GG}, \mathrm{OR}=0.329,95 \%$ CI: 0.146-0.741, $\mathrm{p}=0.006 ; \mathrm{AA} / \mathrm{AG}, \mathrm{OR}=2.316,95 \% \mathrm{CI}: 1.509-$ $3.555, \mathrm{p}=0.001 ; \mathrm{AA} / \mathrm{GG}, \mathrm{OR}=0.761,95 \% \mathrm{CI}$ : $0.363-1.595, \mathrm{p}=0.297$ (Table II).

In our study there was a significant association between MTR 2756 polymorphism and breast cancer risk. So, we conclude that there is a relation between presence of MTR 2756 GG and increase of breast cancer.

\section{Discussion}

In recent years, interest in genetic susceptibility to cancers has led to growing attention to the study of polymorphisms of genes involved in tumourigenesis [17-21]. 


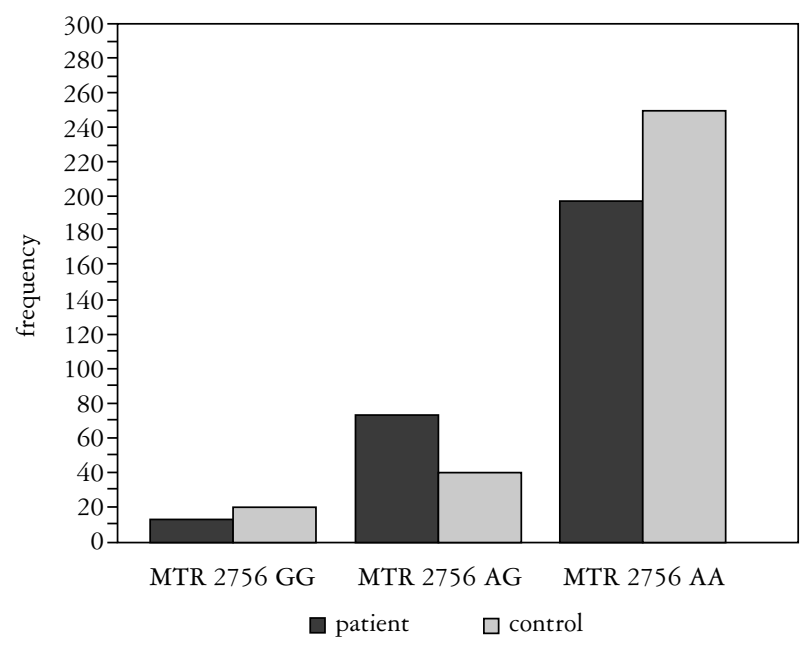

Fig. 1. MTR 2756 genotype frequencies [n (\%)] (Y axes) for cases and controls (X axes): Analyses of 282 affected women and 310 controls for A/G genotype frequency show the highest frequency in both groups of patients (33.3 and 41.4) but in G/C genotype it is significant (12.6 and 6.9) in cases and the control group respectively

Functional polymorphisms in genes encoding onecarbon metabolism enzymes, methylenetetrahydrofolate reductase (MTHFR C677T), methionine synthase (MTR A2756G), methionine synthase reductase (MTRR A66G) and thymidylate synthase (TS), influence folate metabolism, but epidemiological studies have yielded inconsistent findings. In fact, they are enzymes that play a central role in the methyl group metabolic pathway, and that are involved in both DNA methylation and DNA synthesis. Two common functional polymorphisms in the MTHFR gene, C677T (rs1801133) and A1298C (rs1801131), have been published by us already [17]. So we decided to work upon methionine synthase (MTR A2756G).

De Cássia Carvalho Barbosa et al., who worked on patients age 50 years or over, in 2012 [22], Weiner $e t$ al., 2012 by a meta-analysis [23], Suzuki et al., 2008 [24], and Ma et al., 2009, among postmenopausal women [25], did not find any association of MTR A2756G gene polymorphisms with breast cancer risk.

Also in many studies on other cancers, scientists cannot find a significant association, for example, Jackson et al., 2012 [26], in men 40-80 years old in a Jamaican population with prostate cancer and only serum folate was measured by an immunoassay method, Weiner $e t$ al., 2012 [27], with prostatic cancer in the Western Siberian Region of Russia, and Daijun Zhou et al., 2012, by meta-analysis [28], upon colorectal cancer (CRC) in Caucasians.

Many findings suggest that MTR function may induce breast cancer. Carvalho Barbosa Rde et al., 2012, for women $\leq 50$ years, observed a risk in the presence of the polymorphic allele MTR 2756 (AG/GG, $\mathrm{p}=0.0118$ ) and, for over 50, a risk was observed with the MTHFR 677CT genotype [29], so an association
Table II. Comparison between genotypes, odds ratio and $\mathrm{p}$ value showed that $\mathrm{P}$

\begin{tabular}{lccl}
\hline $\begin{array}{l}\text { GeNOTYPE } \\
\text { MTR 2756 }\end{array}$ & OR & 95\% CI & P VAlue \\
\hline AA/AG & 2.316 & $1.509-3.555$ & $0.001^{* * *}$ \\
\hline AG/GG & 0.329 & $0.146-0.741$ & $0.006^{* *}$ \\
\hline AA/GG & 0.761 & $0.363-1.595$ & 0.297 \\
\hline$* * * P \leq 0.001, * * P \leq 0.05$ & &
\end{tabular}

with breast cancer risk was found for Brazilian women carrying the MTR A2756G polymorphic allele $(A G, p=0.0036 ; A G / G G, p=0.0040)$. Naushad et al., 2012 (plasma folate and homocysteine were measured using the Axsym folate kit and reverse phase HPLC, respectively) [30], found an association of (MTR) A2756G (OR: 4.71, 95\% CI: 1.66-13.31) with breast cancer in India, Lu et al., 2010, stratifying by the menopausal status, by meta-analysis [31], suggest that the MTR A2756G polymorphism may contribute to susceptibility to breast cancer among Europeans. Beetstra et al., in 2008 worked upon 3 study groups (mean age $56.4 \pm 2.44$ years, $47.0 \pm 3.12$ years, and $51.0 \pm 2.37$ years for controls) and measured plasma folate $(12.4 \pm 0.9 \mathrm{nmol} / \mathrm{l})$, plasma vitamin $\mathrm{B}_{12}$ (pmol/l) was $249 \pm 17$, and plasma homocysteine $(\mu \mathrm{mol} / \mathrm{l})$ was $7.9 \pm 0.3$ [32], and found that MTR A2756G was associated with increased breast cancer risk [OR: $3.2(\mathrm{p}=0.16$; 95\% CI: 0.76-13.9)].

There are other studies showing that polymorphisms are present in different cancers. For example, Galbiatti et al., 2012 [33], and 2010 in patients at a mean age of $52.5 \pm 13.7$ years [34], conclude that polymorphisms are involved in the risk of head and neck cancer. Guimarães et al., 2011, who worked upon patients aged under 50 years [35], and de Vogel et al., 2009, in patients aged 55 to 69 [36], found an increased risk of sporadic colorectal adenocarcinoma (SCA) in a southeastern population of Brazil and the Netherlands respectively.

Uchida et al., 2011, in adults aged 40-84 years [37], discovered a relation in MTR A2756G homozygotes in human age-related hearing impairment (ARHI) and in an elderly Japanese population. De Lima et al., 2010 [38], suggest an association between the MTR A2756G polymorphism and retinoblastoma susceptibility in a northeast population of Brazil; Ouerhani et al., 2009 [39], found the strongest result obtained with MTR 2756 in affecting bladder cancer risk; Suzuki et al., 2008, in patients aged 20 to 79 years [40], suggest that the folaterelated enzyme polymorphism modifies the association between pancreatic cancer risk, and Lima et al., 2008 [41], suggest a role of the MTR A2756G polymorphism in multiple myeloma risk in Brazil.

In summary, we found that MTR AG was strongly associated with breast cancer risk. It may be that, 
in our statistical analysis, there was a relationship between MTR AA and GG genotype and breast cancer risk, but the number of patients compared to the control group showed a decrease.

In fact, even the AG heterozygous patient number compared to the control number shows an increase.

So, in our study, we conclude that there is a relation between presence of MTR GG and increase of breast cancer risk.

\section{Acknowledgements}

We would like to thank all the patients for their kind collaboration in our projects, and the Islamic Azad University for supporting this research.

Finally, we thank the head and physicians of the Special Medical Centre, Tehran, Iran, who helped us during this project.

\section{The author declares no conflict of interest.}

\section{References}

1. Pufulete M, Al-Ghnaniem R, Leather AJ, et al. Folate status, genomic DNA hypomethylation, and risk of colorectal adenoma and cancer: a case control study. Gastroenterology 2003; 124: $1240-1248$

2. D'Alessio AC, Szyf M. Epigenetic tête-à-tête: the bilateral relationship between chromatin modifications and DNA methylation. Biochem Cell Biol 2006; 84: 463-476.

3. Tuck-Muller CM, Narayan A, Tsien F, et al. DNA hypomethylation and unusual chromosome instability in cell lines from ICF syndrome patients. Cytogenet Cell Genet 2000; 89 121-128.

4. Leclerc D, Campeau E, Goyette P, et al. Human methionine synthase: cDNA cloning and identification of mutations in patients of the cblG complementation group of folate/cobalamin disorders. Hum Mol Genet 1996; 5: 1867-1874.

5. Ehrlich M. The ICF syndrome, a DNA methyltransferase 3B deficiency and immunodeficiency disease. Clin Immunol 2003; 109: $17-28$.

6. Ma J, Stampfer MJ, Christensen B, et al. A polymorphism of the methionine synthase gene: association with plasma folate, vitamin B12, homocyst(e)ine, and colorectal cancer risk. Cancer Epidemiol Biomarkers Prev 1999; 8: 825-829.

7. Leclerc D, Campeau E, Goyette P, et al. Human methionine synthase: cDNA cloning and identification of mutations in patients of the cblG complementation group of folate/cobalamin disorders. Hum Mol Genet 1996; 5: 1867-1874.

8. Goode EL, Potter JD, Bigler J, Ulrich CM. Methionine synthase D919G polymorphism, folate metabolism, and colorectal adenoma risk. Cancer Epidemiol Biomarkers Prev 2004; 13: 157-162.

9. Sharp L, Little J. Polymorphisms in genes involved in folate metabolism and colorectal neoplasia: a HuGE review. Am J Epidemiol 2004; 159: 423-443.

10. Chen K, Song L, Jin MJ, et al. Association between genetic polymorphisms in folate metabolic enzyme genes and colorectal cancer: a nested case-control study. Zhonghua Zhong Liu Za Zhi 2006; 28: 429-432

11. Shi Q, Zhang Z, Li G, et al. Polymorphisms of methionine synthase and methionine synthase reductase and risk of lung cancer: a case-control analysis. Pharmacogenet Genomics 2005; 15: $547-555$.
12. Lissowska J, Gaudet MM, Brinton LA, et al. Genetic polymorphisms in the one-carbon metabolism pathway and Breast cancer risk: a population-based case-control study and meta-analyses. Int J Cancer 2007; 120: 2696-2703.

13. Marchal C, Redondo M, Reyes-Engel A, et al. Association between polymorphisms of folate-metabolizing enzymes and risk of prostate cancer. Eur J Surg Oncol 2008; 34: 805-810.

14. Shin MH, Lee KM, Yang JH, et al. Genetic polymorphism of CYP17 and breast cancer risk in Korean women. Exp Mol Med 2005; 37: 11-17.

15. Artamonov VV, Liubchenko LN, Shabanov MA, et al. Association of polymorphism of genetic markers of CYP19 and CYP17 with sporadic breast cancer. Mol Biol (Mosk) 2003; 37: 975-982.

16. Matsuo K, Suzuki R, Hamajima N, et al. Association between polymorphisms of folate- and methionine-metabolizing enzymes and susceptibility to malignant lymphoma. Blood 2001; 97: 3205-3209.

17. Hosseini M, Houshmand M, Ebrahimi A. MTHFR polymorphisms and breast cancer risk. Arch Med Sci 2011; 7: 134-137.

18. Hosseini M, Houshmand M, Ebrahimi A. RAD51 polymorphisms and breast cancer risk. Mol Biol Rep 2013; 40: 665-668.

19. Mojgan H, Massoud H, Ahmad E. ERCC1 intron 1 was associated with breast cancer risk. Arch Med Sci 2012; 8: 655-658.

20. Hosseini M, Houshmand M, Ebrahimi A. The ERCC2 K751 polymorphism is associated with breast cancer risk. Arch Med Sci 2009; 3: 455-459.

21. Romanowicz-Makowska H, Bryś M, Forma E, et al. Single nucleotide polymorphism (SNP) Thr241Met in the XRCC3 gene and breast cancer risk in Polish women. Pol J Pathol 2012; 2: 121-125.

22. de Cássia Carvalho Barbosa R, da Costa DM, Cordeiro DE, et al. Interaction of MTHFR C677T and A1298C, and MTR A2756G gene polymorphisms in breast cancer risk in a population in Northeast Brazil. Anticancer Res 2012; 32: 4805-4811.

23. Weiner AS, Boyarskikh UA, Voronina EN, et al. Polymorphisms in the folate-metabolizing genes MTR, MTRR, and CBS and Breast cancer risk. Cancer Epidemiol 2012; 36: e95-e100.

24. Suzuki T, Matsuo K, Hirose K, et al. One-carbon metabolismrelated gene polymorphisms and risk of breast cancer. Carcinogenesis 2008; 29: 356-362.

25. Ma E, Iwasaki M, Kobayashi M, et al. Dietary intake of folate, vitamin B2, vitamin B6, vitamin B12, genetic polymorphism of related enzymes, and risk of breast cancer: a case-control study in Japan. Nutr Cancer 2009; 61: 447-456.

26. Jackson MD, Tulloch-Reid MK, McFarlane-Anderson N, et al. Complex interaction between serum folate levels and genetic polymorphisms in folate pathway genes: biomarkers of prostate cancer aggressiveness. Genes Nutr 2013; 8: 199-207.

27. Weiner AS, Oskina NA, Lacarev AF, et al. Role of polymorphic variants of MTR gene A2756G and SHMT1 gene C1420T in the development of prostatic cancer in residents of the Western Siberian Region of Russia. Bull Exp Biol Med 2012; 152: 466-469.

28. Zhou D, Mei Q, Luo H, et al. The polymorphisms in methylenetetrahydrofolate reductase, methionine synthase, methionine synthase reductase, and the risk of colorectal cancer. Int J Biol Sci 2012; 8: 819-830.

29. Carvalho Barbosa Rde C, Menezes DC, Freire TF, et al. Associations of polymorphisms of folate cycle enzymes and risk of Breast cancer in a Brazilian population are age dependent. Mol Biol Rep 2012; 39: 4899-4907.

30. Naushad SM, Pavani A, Rupasree Y, et al. Association of aberrations in one-carbon metabolism with molecular phenotype and grade of breast cancer. Mol Carcinog 2012; 51 Suppl 1: E32-41.

31. Lu M, Wang F, Qiu J. Methionine synthase A2756G polymorphism and breast cancer risk: a meta-analysis involving 18,953 subjects. Breast Cancer Res Treat 2010; 123: 213-217. 
32. Beetstra S, Suthers G, Dhillon V, et al. Methionine-dependence phenotype in the de novo pathway in BRCA1 and BRCA2 mutation carriers with and without breast cancer. Cancer Epidemiol Biomarkers Prev 2008; 17: 2565-2571.

33. Galbiatti AL, Ruiz MT, Maniglia JV, et al. Head and neck cancer: genetic polymorphisms and folate metabolism. Braz J Otorhinolaryngol 2012; 78: 132-139.

34. Galbiatti AL, Ruiz MT, Biselli-Chicote PM, et al. 5-Methyltetrahydrofolate-homocysteine methyltransferase gene polymorphism (MTR) and risk of head and neck cancer. Braz J Med Biol Res 2010; 43: 445-450.

35. Guimarães JL, Ayrizono Mde L, Coy CS, Lima CS. Gene polymorphisms involved in folate and methionine metabolism and increased risk of sporadic colorectal adenocarcinoma. Tumour Biol 2011; 32: 853-861.

36. de Vogel S, Wouters KA, Gottschalk RW, et al. Genetic variants of methyl metabolizing enzymes and epigenetic regulators: associations with promoter $\mathrm{CpG}$ island hypermethylation in colorectal cancer. Cancer Epidemiol Biomarkers Prev 2009; 18: 3086-3096.

37. Uchida Y, Sugiura S, Ando F, et al. Hearing impairment risk and interaction of folate metabolism related gene polymorphisms in an aging study. BMC Med Genet 2011; 12: 35.

38. de Lima EL, da Silva VC, da Silva HD, et al. MTR polymorphic variant A2756G and retinoblastoma risk in Brazilian children. Pediatr Blood Cancer 2010; 54: 904-908.

39. Ouerhani S, Rouissi K, Marrakchi R, et al. Combined effect of NAT2, MTR and MTHFR genotypes and tobacco on bladder cancer susceptibility in Tunisian population. Cancer Detect Prev 2009; 32: 395-402.

40. Suzuki T, Matsuo K, Sawaki A, et al. Alcohol drinking and onecarbon metabolism-related gene polymorphisms on pancreatic cancer risk. Cancer Epidemiol Biomarkers Prev 2008; 17: $2742-2747$.

41. Lima CS, Ortega MM, Ozelo MC, et al. Polymorphisms of methylenetetrahydrofolate reductase (MTHFR), methionine synthase (MTR), methionine synthase reductase (MTRR), and thymidylate synthase (TYMS) in multiple myeloma risk. Leuk Res 2008; 32: 401-405.

\section{Address for correspondence}

Mojgan Hosseini PhD

Department of Science

Islamshahr Branch

Islamic Azad University

Sayad Shirazi

St. Islamshahr

Tehran, Iran

tel./fax +98-21-66936779

e-mail: moj.hosseini@gmail.com 